\title{
Treating the elderly diabetic patient: special considerations
}

This article was published in the following Dove Press journal:

Diabetes, Metabolic Syndrome and Obesity: Targets and Therapy

28 August 2014

Number of times this article has been viewed

\section{Louise Kezerle \\ Leah Shalev \\ Leonid Barski}

Department of Internal Medicine F, Soroka University Medical Center, Beer-Sheva, Israel
Correspondence: Leonid Barski Department of Internal Medicine F, Soroka University Medical Center, PO Box I5I, Beer-Sheva 84I0I, Israel $\mathrm{Tel}+97286403431$

Fax +972 86400097

Email lbarski@bgu.ac.il
Abstract: The prevalence of diabetes is rising in the $>65$ year-old group. The challenge of defining the goals of therapy arises from the heterogeneity of the aging process and the sparse clinical data in this patient population. In light of these challenges, the clinician should be aware of the pitfalls of caring for the older diabetic patient and prioritize an individualized treatment plan to ensure an optimal glycemic control, without placing the patient at unnecessary risk. We present a review of the current guidelines and literature that deal specifically with the treatment of the older diabetic patient in order to establish the principles of treatment in this age group and help the clinician make decisions regarding the care of these patients.

Keywords: diabetes treatment, elderly, review

\section{Introduction}

Diabetes mellitus type 2 (DM2) and its complications remain major causes of morbidity and mortality worldwide. Data available from multiple sources in the US ${ }^{1}$ show that approximately $8.6 \%$ of the US population is diabetic and that this number has been steadily increasing in the last few decades. ${ }^{2,3}$ In the population over 65 years of age, the estimate is even more alarming: 10.9 million people or $26.9 \%$ of all people in this age group suffered from diabetes in $2010 .^{1}$

The elderly also take a bigger toll for this disease since DM2 in older adults is linked to increased mortality and complication rates when compared to young diabetics ${ }^{4}$ and to people in the same age group without DM2. ${ }^{5}$

The treatment of DM2 is especially challenging in this population due to cognitive disorders, physical disabilities, higher risk of hypoglycemia, and the high rate of comorbidities leading to polypharmacy. ${ }^{4}$ Therapeutic goals and the selection of drugs may not be the same for elderly and younger patients. Hence, the purpose of this article is to review the current literature on particularities of DM2 treatment in the age group of 65 years and older.

\section{Heterogeneity}

The first challenge in treating older adults with DM2 is that they constitute a very diverse group: from healthy, working individuals to those functionally and cognitively frail, living in nursing homes.

Furthermore, there are variable degrees of insulin deficiency, as well as peripheral and hepatic insulin resistance and these differences should be taken into account, together with socioeconomic status, living situation, and lifestyle when choosing appropriate treatment goals and therapeutic options. 


\section{Evidence that supports treatment and individualized glycemic target}

Despite years of diabetes research, specific data about the benefits of diabetes treatment on older adults are scarce. The UK Prospective Diabetes Study (UKPDS) was the first large randomized controlled trial to provide concrete evidence of the value of glycemic control on diabetic microvascular complications, but it excluded patients aged 65 and older at the time of enrollment to the study. ${ }^{6,7}$ Since then, studies that were designed to study patients with long-standing DM2 have examined an older population, with mixed results.

In accordance with the results of the UKPDS, the Action in Diabetes and Vascular Disease: Preterax and Diamicron MR Controlled Evaluation (ADVANCE) trial ${ }^{8}$ showed a reduction of diabetic nephropathy with intensive glycemic control, but failed to demonstrate a cardiovascular benefit after a median follow-up of 5 years. The trial only enrolled patients 55 years and older and included a subgroup analysis of patients over 65 with no statistical difference in the outcomes.

The Action to Control Cardiovascular Risk in Diabetes (ACCORD) trial $^{9}$ demonstrated a decrease only in diabetic nephropathy with intensive glycemic control even though patients on this arm of the study were transitioned to standard therapy after a median follow-up of 3.7 years due to an increase in total and cardiovascular mortality. The mean age was 62.2 years and a subgroup analysis suggested that the risk for cardiovascular mortality was disproportionally high among patients under 65 years of age.

Finally, the Veteran's Affairs Diabetes Trial,${ }^{10}$ found that intensive glucose control in patients with poorly controlled DM2 and a mean age of 60 years had no significant effect on the rates of major cardiovascular events, death, or microvascular complications, with the exception of progression of albuminuria over a follow-up of 5 years.

Although indisputable evidence on the impact of glycemic control in diabetic macrovascular complications is lacking, several observational studies have verified a correlation between high $\mathrm{A}_{1 \mathrm{c}}$ levels $(>8 \%)$ and increased mortality and cardiovascular events in older adults. ${ }^{11,12}$ Moreover, hyperglycemia in itself has negative physiologic consequences: osmotic diuresis leading to dehydration, impaired vision, and decreased cognition. ${ }^{6}$

On the other hand, elderly patients are at increased risk of hypoglycemia with intensive glycemic control. These episodes may have especially severe consequences in older adults, such as falls and traumatic fractures, exacerbation of comorbidities with adverse cardiovascular events, ${ }^{13}$ impaired $\operatorname{cognition}^{14}$ and function. Observational studies have even demonstrated excess mortality associated with near-normal $\mathrm{A}_{1 \mathrm{c}}(<6 \%)$ goals. ${ }^{11}$ In addition, hypoglycemia in the older individual presents with neurological symptoms such as dizziness, weakness, and confusion and less frequently with the adrenergic manifestations (sweats, tremor), and these less specific symptoms are less likely to be associated with hypoglycemia, which leads to fewer reports and diagnosis of these episodes.

In light of the available data, the American Diabetes Association (ADA) ${ }^{13}$ and the European Diabetes Working Party ${ }^{14}$ guidelines recommend an $A_{1 c}$ goal of $7 \%$ in nonpregnant adults with recently diagnosed DM2 who have a life expectancy of over 10 years. Less stringent $\mathrm{A}_{1 \mathrm{c}}$ goals (probably $<8 \%$ ) may be appropriate for patients with limited life expectancy, history of severe hypoglycemia, advanced micro or macrovascular disease, and extensive comorbid conditions. It is imperative to remember that when treating elderly patients with DM2, an individualized goal to preserve quality of life and avoid side-effects of therapy is key.

\section{Where to start - lifestyle changes}

Although most patients with DM2 will require medication over the course of their disease, ${ }^{15}$ there is enough evidence to support the fact that older persons can respond well to nutrition therapy and exercise.

Medical nutrition therapy (MNT) consists of individualized dietary instruction that incorporates diet therapy counseling for a nutrition-related problem. It has been an aid in preventing DM2, managing existing DM2, and slowing the rate of development of DM2 complications. ${ }^{16}$ One randomized trial of medical nutrition intervention on 98 adults $\geq 65$ years of age demonstrated greater improvements on fasting plasma glucose and $\mathrm{A}_{1 \mathrm{c}}$ than control patients. ${ }^{17}$ This tailored approach to nutrition counseling is especially important in the elderly since this population is highly heterogeneous and although weight reduction may benefit obese or overweight patients, many older adults are frail and actually suffer from undernutrition and micronutrient deficiency.

For an obese individual, the ADA recommends a modest weight loss of $5 \%-10 \%$ body weight, while physical activity can help attenuate loss of lean body mass that can occur with energy restriction. ${ }^{16}$ Furthermore, exercise training can reduce the decline in maximal aerobic capacity that occurs with age, augment insulin sensitivity, and improve other risk factors for atherosclerosis. ${ }^{18}$ Again, individualization is fundamental when it comes to exercise since unsupervised exercise practice holds potential risks for instance hypoglycemia, physical injury, and cardiac events. 


\section{Pharmacological treatment}

Most trials of drugs to treat DM2 included a wide range of patients, including those over 65 years of age, so the results of these trials probably apply to this population. Nevertheless, doctors caring for elderly diabetic patients should be aware of the pharmacological changes that occur with aging in order to avoid common side-effects and maximize the chances of adequate glycemic control.

First of all, age is associated with change in some pharmacokinetic parameters, such as impaired elimination due to decreased renal function and phase I liver metabolism as well as altered drug distribution owing to an increase in body fat and a reduction in lean body mass. ${ }^{19-21}$ These phenomena together with a slow counter-regulatory hormone secretion explain why the elderly are more prone to hypoglycemia when treated with insulin or insulin-releasing agents. ${ }^{22}$ Likewise, pharmacodynamic changes may also affect the sensitivity of older adults to drugs. Hence, these issues should be considered when choosing a drug and dosage to treat DM2 in this population. Consideration to the patient's physical abilities, cognitive function, comorbidities, and preference should also be given. The axiom "start low and go slow" should always be kept in mind.

\section{Oral therapy Metformin}

Metformin is the only biguanide available for clinical use and represents one of two classes of drugs that improve sensitivity to insulin. It acts mainly by sensitizing the liver to the effects of insulin thereby decreasing hepatic glucose output, but has additional effects on improving insulin sensitivity in peripheral tissues and lowering serum free fatty acid concentrations. ${ }^{23-25}$

Metformin typically lowers fasting blood glucose by $20 \%$ and $\mathrm{A}_{1 \mathrm{c}}$ levels by $1.5 \% .{ }^{26,27}$ Given the long-standing evidence base for its efficacy and safety, the ADA recommends metformin as the first-line pharmacological therapy for patients with DM2, barring contraindication or intolerance. ${ }^{13}$ Other benefits of metformin use are promotion of modest weight reduction in overweight and obese patients, improvement in lipid profile, and a potential reduction in cardiovascular events and all-cause mortality. ${ }^{28}$ The main advantage of this drug for the elderly population, however, is the very low risk of hypoglycemia with monotherapy. ${ }^{29}$

The most common side-effects of metformin use are gastrointestinal: a metallic taste in the mouth, nausea and vomiting, abdominal discomfort, and diarrhea. ${ }^{24}$ Although clinical trials have revealed that only $5 \%$ of the subjects dis- continue metformin because of gastrointestinal symptoms, these may be especially worrisome in the frail elderly population with poor appetite and low daily caloric intake. In addition, long term treatment with metformin increases the risk of vitamin B12 deficiency, ${ }^{30}$ so levels of this vitamin should be monitored during metformin use and a supplementation should be offered to at risk patients.

The most dreaded side-effect of metformin, however, is lactic acidosis. The incidence of metformin-induced lactic acidosis (MALA) appears to be exceedingly low (about 9 cases per 100,000 person-years of exposure) $)^{31}$ with a recent meta-analysis of over 70,000 patients on metformin failing to attest to an association between the drug and the development of lactic acidosis. ${ }^{32}$ On the other hand, the high case-fatality rate of this adverse effect makes it a genuine concern for doctors caring for diabetic patients. Since most cases have occurred in patients with the other predisposing conditions, prescribing guidelines recommend refraining from metformin use in patients with impaired renal function, concurrent liver disease or alcohol abuse, advanced heart failure, past history of lactic acidosis, and in the event of decreased tissue perfusion. ${ }^{33}$ Of these risk factors, renal failure is the most significant in terms of established evidence. Even though the classic definition utilizes a threshold of serum creatinine of $1.5 \mathrm{mg} / \mathrm{dL}$ for men and $1.4 \mathrm{mg} / \mathrm{dL}$ for women, these criteria are not sufficiently accurate for estimating renal function in elderly patients with reduced muscle mass. Therefore, an estimated glomerular filtration rate (GFR) should be calculated to limit the utilization of metformin more precisely. Some experts recommend a GFR $>30 \mathrm{~mL} / \mathrm{min}$ as a safe threshold for metformin use but a GFR between 30 and $60 \mathrm{~mL} / \mathrm{min}$ should be viewed as a relative contraindication and prescription of a lower dose should be advised..$^{29,34,35} \mathrm{It}$ is also imperative to warn patients to stop taking metformin if they become acutely ill or before receiving intravenous iodinated contrast material. When these recommendations are met, the risk of MALA is close to zero.

\section{Sulfonylureas}

Sulfonylureas are insulin secretagogues and as such they stimulate insulin release from pancreatic beta cells. They reduce $\mathrm{A}_{1 \mathrm{c}}$ to an extent similar to metformin $(1 \%-2 \%)^{36}$ and are usually well tolerated, which makes this class one of the most widely used in the treatment of DM2. ${ }^{37}$ Hypoglycemia is the main side-effect of these drugs and the risk of this complication is especially high in the elderly ${ }^{38}$ and with longacting sulfonylureas, such as chlorpropamide and glyburide. ${ }^{39}$ As a result, the ADA recommends the use of shorter acting 
drugs, for example glipizide, to be prescribed in low starting doses. Furthermore, use of sulfonylureas should be avoided in patients with impaired renal, cardiac or gastrointestinal function, in those who are undernourished or abuse alcohol, and after a hospital stay. ${ }^{40}$ Finally, patients should be warned not to miss meals during treatment with a sulfonylurea.

Another concern of sulfonylurea treatment is the alleged association with increased mortality from cardiovascular disease. This was first noted in the University Group Diabetes Study, ${ }^{41}$ and since then several studies have been conducted to investigate this association, with no ultimate conclusions. On one hand, retrospective studies have shown an increase in incidence and mortality from cardiovascular events in patients taking sulfonylurea in comparison to metformin. ${ }^{42-45}$ On the other hand, the UKPDS ${ }^{46}$ did not report an increase in cardiovascular mortality related to sulfonylureas and a recent meta-analysis of trials comparing newer sulfonylureas with other anti-diabetic drugs evidenced no difference in cardiovascular mortality. ${ }^{47}$ These differences may be due to the fact that second-generation sulfonylureas are selective for the pancreatic sulfonylurea receptors and the toxicity of older sulfonylureas is related to the effect on adenosine triphosphate (ATP)-dependent potassium channels on cardiac cells and coronary vessels.

\section{Meglitinides}

The meglitinides function as short-acting insulin secretagogues, but through different receptors than sulfonylureas. Their clinical efficacy in lowering $A_{1 c}$ is similar to sulfonylureas. ${ }^{48}$ The most common side-effect of meglitinide treatment is hypoglycemia, which occurs at a similar frequency as with sulfonylurea use. ${ }^{49}$ Since repaglinide is metabolized by the liver, it may be an option for treatment of DM2 in older patients with renal impairment.

\section{Thiazolidinediones}

Thiazolidinediones (TZDs) are the second class of insulin sensitizers. They reduce insulin resistance in peripheral tissue and also decrease hepatic gluconeogenesis. ${ }^{50}$ Their use has been drastically limited in the past years due to concerns about worsening heart failure due to fluid retention, ${ }^{50}$ decreased bone density, ${ }^{51}$ and increased risk of bladder cancer. ${ }^{52}$ There was also concern regarding an increased risk of cardiovascular events with rosiglitazone following the results of a large population-based study of older ( $\geq 65$ years) patients with DM2 that showed an increased risk of myocardial infarction with use of rosiglitazone ${ }^{53}$ even though these findings were not consistent among similar studies. $^{54-56}$
Since most of the studies mentioned were not designed to directly assess cardiovascular outcomes, the Rosiglitazone Evaluated for Cardiac Outcome and Regulation of Glycaemia in Diabetes (RECORD) ${ }^{57}$ study was performed to specifically examine the effects of rosiglitazone treatment on cardiovascular disease. In its final analysis, the study showed an increased risk of fatal and non-fatal myocardial infarction in the group treated with rosiglitazone in addition to metformin and sulfonylureas when compared to the control group, which was treated with metformin and sulfonylureas alone, although the low event rate and high drop-out rate diminished the power of the analysis.

Following the publication of this study in 2010, rosiglitazone was removed from the European market and in the US, the US Food and Drug Administration (FDA) restricted its use by making it available only through a Risk Evaluation and Mitigation Strategy.

More recently, an independent review of the original data of the RECORD study did not find an increase in cardiovascular risk in the group treated with rosiglitazone and even suggests that the drug might have a protective effect on cardiovascular outcomes, although this benefit was not statistically significant. Based on these findings, the FDA has required removal of the prescribing and dispensing restrictions for rosiglitazone that were put in place in $2010 .^{58}$

Until more definite data on the cardiovascular safety of TZDs are available, they will probably remain a second-line option for patients who have not achieved their glycemic targets on alternative therapies (metformin, sulfonylureas, insulin). Still, since TZDs do not cause hypoglycemia and can be given to patients with renal failure they can be a useful option for elderly patients. The clear decrease in bone density $^{59}$ and slightly elevated risk of fractures ${ }^{60}$ associated with TZD treatment should also be taken into consideration when prescribing these drugs to older women.

\section{Alpha-glucosidase inhibitors}

Alpha-glucosidase is a gastrointestinal enzyme that converts complex polysaccharide carbohydrates into monosaccharides, so its inhibition slows the absorption of glucose, lowering post-prandial blood glucose concentrations.

Acarbose and miglitol are the available drugs in this class and have a slightly lower efficacy when compared to the aforementioned treatments, lowering $\mathrm{A}_{1 \mathrm{c}}$ levels by $0.5 \%-1 \%{ }^{61}$ They have a favorable safety profile, since they do not cause hypoglycemia or other severe adverse effects. Nonetheless, the use of these drugs is limited by 
gastrointestinal side-effects, such as flatulence and diarrhea, which are particularly common in older adults. ${ }^{62}$

\section{Dipeptidyl peptidase-4 inhibitors}

By inhibiting dipeptidyl peptidase-4 (DPP-4), the enzyme responsible for degrading incretins, mainly glucose-dependent insulinotropic polypeptide (GIP) and glucagon-like peptide-1 (GLP1), DDP-4 inhibitors increase insulin synthesis and release and decrease glucagon production, resulting in a reduction in blood glucose concentration. ${ }^{63}$ Agents in this class are considered relatively weak agents, as they usually lower $\mathrm{A}_{1 \mathrm{c}}$ by only $0.6 \%$; there does not seem to be variation in efficacy among the different drugs available (sitagliptin, saxagliptin, vildagliptin, linagliptin, and alogliptin). ${ }^{64}$

Since the insulin release mediated by GLP-1 is dependent on blood glucose concentration, the risk of hypoglycemia of GLP-1 based therapies is negligible, which would make this a favorable option in the treatment of older adults. It is important to note, however, that long-term safety with DDP-4 has not been established and reported side-effects include worsening heart failure, ${ }^{65}$ headaches, elevated incidence of nasopharyngitis and upper respiratory tract infections, ${ }^{64}$ pancreatitis ${ }^{66}$ and hypersensitivity reactions, including angioedema, anaphylaxis and Stevens-Johnson syndrome. ${ }^{67}$ Finally, dose adjustment is recommended for patients with moderate to severe renal impairment, defined as a GFR $\leq 50 \mathrm{~mL} / \mathrm{min}^{6}{ }^{6}$

\section{Sodium-glucose co-transporter 2 inhibitors}

The sodium-glucose co-transporter 2 (SGLT2) is a cotransporter that is expressed in the proximal tubule and is responsible for reabsorbing approximately $90 \%$ of the filtered glucose load. ${ }^{69}$ Its inhibition can lead to a subtle lowering of blood glucose levels. According to data available from a metaanalysis of clinical trials comparing SGLT2 inhibitors with placebo or other available drugs, SGLT2 inhibitors reduced $\mathrm{A}_{1 \mathrm{c}}$ by approximately 0.5 to 0.7 percentage points, making them relatively weak glucose-lowering agents. ${ }^{70}$

Dapagliflozin and canagliflozin are available in Europe and the US. ${ }^{71,72}$ These drugs have been studied as monotherapy and in combination with metformin, sulfonylureas, pioglitazone, sitagliptin, and insulin. ${ }^{73-75}$ Although the clinical experience with these drugs is still limited, they may represent an important new option for the treatment of DM2 due to the low incidence of hypoglycemia and added benefit of decreasing blood pressure and weight. ${ }^{69}$ The main side-effect described so far is an increased incidence of vulvovaginal candidiasis in women. ${ }^{76,77}$

\section{Injectable therapy GLP-I analogs}

GLP-1 is a gastrointestinal hormone which is involved in glucose homeostasis primarily by stimulating glucosedependent insulin release from pancreatic islets, but has also been shown to slow gastric emptying, ${ }^{78}$ inhibit post-meal glucagon release, and increase satiety in the brain, thereby leading to reduced food intake. ${ }^{79}$ In view of these effects, GLP-1 analogs have been developed and are available for use in patients with DM2.

Exenatide and liraglutide are the two drugs in this class. Randomized trials have demonstrated that both drugs are effective in reducing blood glucose, lowering $\mathrm{A}_{\mathrm{lc}}$ by about $1 \%{ }^{80-82}$ In addition, treatment with GLP-1 analogs results in progressive and dose-dependent weight loss. ${ }^{83,64}$ This may represent an added benefit of this therapy to overweight and obese patients, but because many elderly patients are frail and undernourished, this effect may actually be detrimental and should be taken into account when initiating treatment with these agents. Moreover, nausea and vomiting are common side-effects of GLP-1 analogs, which may further limit their use in the elderly population. These gastrointestinal effects, however, may be avoided with dose titration and usually wane with continuation of therapy. ${ }^{84}$

Hypoglycemia is an uncommon occurrence with monotherapy with GLP-1 analogs, ${ }^{85}$ but these agents may elevate the risk of sulfonylurea induced hypoglycemia, ${ }^{81}$ so it is recommended that the dose of the sulfonylurea be reduced on initiation of exenatide or liraglutide.

Other adverse effects have been documented during treatment with GLP-1 analogs in post-marketing reports: acute pancreatitis with both exenatide ${ }^{85}$ and liraglutide and acute renal failure with exenatide. Although a clear causal relationship has yet to be established between worsening of renal function and use of exenatide, this drug should not be administered to patients with GFR below $30 \mathrm{~mL} / \mathrm{min}$ and creatinine monitoring is recommended when initiating therapy. ${ }^{86}$

\section{Pramlintide}

Pramlintide is an amylin analog that is administered subcutaneously at mealtime and reduces post-prandial glucose levels by slowing gastric emptying, promoting satiety, and suppressing the rise of glucagon. ${ }^{87,88}$ It has been approved only for patients who are also taking prandial insulin and provides a modest additional reduction in $\mathrm{A}_{1 \mathrm{c}}$ of about $0.6 \%{ }^{89}$ The role of this drug in the treatment of DM2 is not yet clear and its use is limited in the elderly by the need for multiple subcutaneous 
injections, increased risk of severe hypoglycemia, and lack of data on long-term outcomes.

\section{Insulin}

Due to progressive loss of beta-cell function that characterizes DM2, most individuals will ultimately require insulin therapy to control hyperglycemia. ${ }^{90}$ Concern of hypoglycemia and of difficulty of administration should not prevent an elderly patient from enjoying the benefits of improved glycemic control with insulin treatment, for example improved quality of life and vitality. ${ }^{91}$ Nonetheless, before initiating insulin therapy, it is important to evaluate whether the patient is cognitively and physically capable of injecting insulin in the correct dose, monitoring blood glucose, and recognizing and managing hypoglycemia.

A position statement by the ADA/EASD (European Association for the Study of Diabetes) $)^{92}$ suggests that unless the patient is markedly hyperglycemic or symptomatic, a "basal" insulin alone be added as an initial step to oral hypoglycemic therapy, in order to provide a relatively uniform insulin throughout the day and night. The long acting insulin analogs glargine and detemir and the intermediate-acting insulin neutral protamine Hagedorn (NPH) are the available options but NPH has been consistently associated with a significantly elevated risk of hypoglycemia ${ }^{93-95}$ so it is less desirable to be used as basal insulin, especially in the elderly.

As beta-cell function declines further, prandial insulin coverage may be necessary in some patients. Basal-bolus regimens comprising of multiple injections may pose a challenge to older patients, so this type of therapy may be suitable only to a small group of well-functioning elderly patients.

Because insulin metabolism is altered in renal insufficiency, its dose should be decreased when GFR is below $50 \mathrm{~mL} / \mathrm{min}$ in order to avoid hypoglycemia. Moreover, patients taking insulin should be advised not to skip meals and closely monitor glucose levels when they feel ill. The other notable side-effect of insulin treatment is weight gain, which is less pronounced with insulin detemir. ${ }^{96,97}$

\section{Approach to the patient: algorithm for DM2 treatment}

Since large randomized controlled trials of DM2 treatment targeting the population 65 years and older are scarce, treatment recommendations for older adults are extrapolated from studies on the general population that included patients in this age group.

According to the ADA/EADS position statement, metformin should be the first-line drug therapy in hyperglycemic patients in whom lifestyle intervention alone has not achieved, or is unlikely to achieve $\mathrm{A}_{1 \mathrm{c}}$ goals, and who do not have contraindications to its use.

For patients who do not achieve their targets with lifestyle modification and metformin alone, additional therapy is indicated and should be chosen in light of the safety profile of each drug and possible adverse effects. Addition of longacting basal insulin or a short acting sulfonylurea might be preferred in the elderly due to a longer experience and research with these drugs; hypoglycemia is a concern and should be closely monitored. The other drugs previously mentioned are less validated but possible add-on therapies for the elderly. Lastly, if optimal hyperglycemia control is not achieved or if comorbidities preclude the use of other drugs, prandial insulin coverage may be needed, usually in a basal-bolus regimen.

An important issue in the care of the elderly diabetic patient is the most appropriate recommended monitoring of therapy efficacy. Measurement of $A_{1 c}$ may not be accurate in some conditions seen frequently in older adults: anemia, chronic kidney disease, recent acute illness or hospitalization, chronic liver disease, red blood cell transfusions, and use of erythropoietin. ${ }^{98}$ Nonetheless, the $\mathrm{A}_{1 \mathrm{c}}$ is still the best tool for assessing long-term glycemic control and so it should be measured quarterly in patients who are undergoing changes in therapy or who are not meeting glycemic goals and twice a year for those who are on stable therapy.

Self-monitoring of blood glucose may be helpful to prevent hypoglycemia in patients who are treated with insulin or sulfonylureas, but it requires functional and cognitive capabilities and thus may only be employed in selected elderly patients. ${ }^{4}$

\section{Managing complications and comorbidities}

As with younger patients, glycemic control is the most important prevention strategy for avoiding microvascular complications such as diabetic nephropathy and neuropathy. Nonetheless, early recognition and aggressive treatment of these problems is also beneficial and so all elderly diabetic patients should be advised and referred to regular evaluations.

A complete eye exam at least once a year is mandatory since poor vision can lead to social withdrawal, recurrent falls and their consequences and difficulty in measuring blood glucose and managing diabetes treatment.

A yearly screening for increased urinary albumin excretion can identify patients with microalbuminuria who benefit greatly from treatment with angiotensin-converting-enzyme 
inhibitor (ACEi) or angiotensin II receptor blockers (ARBs). This is true for diabetic patients across all age groups and the population over 65 years is no exception.

Finally, foot-care is key for every diabetic patient for it helps avoid the development of ulcers and prevents amputations. Diabetic neuropathy is one of the contributors of foot lesions and is especially common in the elderly, with a prevalence of more than $50 \%$ in patients over $60,{ }^{99}$ furthermore, functional decline may prevent the older patient from reaching or seeing their feet for routine checks. For all these reasons, a detailed examination of the feet must be a part of every visit of diabetic patients with their personal physician.

Coronary artery disease is a leading cause of death in elderly patients. Due to its multifactorial etiology, a global approach for risk factor reduction is fundamental in avoiding the development of cardiovascular diseases. This approach starts with optimal glycemic control as described previously and includes treatment of other comorbidities such as hypertension ${ }^{100}$ and dyslipidemia ${ }^{101}$ as well as smoking cessation, ${ }^{102}$ regular physical exercise and weight reduction, and finally, primary or secondary prevention with aspirin. ${ }^{103}$ The goals for each of these risk factors should also be adjusted to the patient's preferences, life expectancy, and cognitive status, with a more aggressive approach being adequate in more functional individuals.

Cognitive function should be frequently assessed in elderly patients because DM is a significant risk factor for the development of dementia. This can manifest as non-compliance with hypoglycemic therapy, deterioration of glycemic control, and an increase in episodes of hypoglycemia. ${ }^{104}$

Depression may also have an influence on glycemic control and has been associated with accelerated rates of coronary heart disease ${ }^{105}$ in diabetic patients. Short screening tools (such as the "Geriatric Depression Scale") are available and should be used to identify those with symptoms of depression since the treatment of this comorbidity can also help achieve glycemic goals. ${ }^{106}$

Use of multiple drugs is common in older adults. Management of hyperglycemia and its associated risk factors often increases the number of medications even more in the elderly with DM2. Side-effects may exacerbate comorbidities and impede the patient's ability to manage his/her diabetes. Therefore, the medication list should be kept current and reviewed at each visit. ${ }^{4,11}$

\section{Nursing home patients}

There are few studies and guidelines directed at care of older adults with DM2 residing in nursing homes.
Life expectancy, quality of life, severe functional disabilities, and other co-existing conditions mentioned previously affect goal setting and management plans. Exercise as tolerated in any form continues to be important for all patients. Regular diet without concentrated sweets may improve quality of life and prevent weight loss.

Treatment regimens should be chosen to achieve maximal glycemic control possible, with a focus on avoidance of hypoglycemia and control of hyperglycemic symptoms.

\section{Conclusion}

The prevalence of diabetes is rising in the $>65$ year-old group. The challenge of defining the goals of therapy arises from the heterogeneity of both the aging process along with the sparse clinical data in this patient population. In light of these challenges, the clinician should be aware of the pitfalls of caring for the older diabetic patient and prioritize an individualized treatment plan to ensure an optimal glycemic control, without placing the patient at unnecessary risk.

\section{Disclosure}

The authors have no conflicts of interest to disclose.

\section{References}

1. Centers for Disease Control and Prevention. 2011 National Diabetes Fact Sheet. Available from: http://www.cdc.gov/diabetes/pubs/pdf/ ndfs_2011.pdf. Accessed January 20, 2014.

2. Cowie CC, Rust KF, Ford ES, et al. Full accounting of diabetes and prediabetes in the US population in 1988-1994 and 2005-2006. Diabetes Care. 2009;32:287-294.

3. Fox CS, Pencina MJ, Meigs JB, et al. Trends in the incidence of type 2 diabetes mellitus from the 1970s to the 1990s: the Framingham Heart Study. Circulation. 2006;113(25):2914-2918.

4. Sue Kirkman M, Briscoe VJ, Clark N, et al. Diabetes in older adults: a consensus report. J Am Geriatr Soc. 2012;60(12):2342-2356.

5. Bethel MA, Sloan FA, Belsky D, Feinglos MN. Longitudinal incidence and prevalence of adverse outcomes of diabetes mellitus in elderly patients. Arch Intern Med. 2007;167(9):921-927.

6. No authors listed. Intensive blood-glucose control with sulphonylureas or insulin compared with conventional treatment and risk of complications in patients with type 2 diabetes (UKPDS 33). UK Prospective Diabetes Study (UKPDS) Group. Lancet. 1998;352(9131):837-853.

7. Holman RR, Paul SK, Bethel MA, et al. 10-year follow-up of intensive glucose control in type 2 diabetes. $N$ Engl J Med. 2008;359(15): 1577-1589.

8. ADVANCE Collaborative Group, Patel A, MacMahon S, et al. Intensive blood glucose control and vascular outcomes in patients with type 2 diabetes. N Engl J Med. 2008;358(24):2560-2572.

9. Action to Control Cardiovascular Risk in Diabetes Study Group, Gerstein HC, Miller ME, et al. Effects of intensive glucose lowering in type 2 diabetes. $N$ Engl J Med. 2008;358(24):2545-2559.

10. Duckworth W, Abraira C, Moritz T, et al. Glucose control and vascular complications in veterans with type 2 diabetes. $N$ Engl J Med. 2009;360(2):129-139.

11. Currie CJ, Peters JR, Tynan A, et al. Survival as a function of $\mathrm{HbA}(1 \mathrm{c})$ in people with type 2 diabetes: A retrospective cohort study. Lancet. 2010;375(9713):481-489. 
12. Huang ES, Liu JY, Moffet HH, et al. Glycemic control, complications, and death in older diabetic patients: The Diabetes and Aging Study. Diabetes Care. 2011;34(6):1329-1336.

13. American Diabetes Association. Standards of medical care in diabetes 2013. Diabetes Care. 2013;36 Suppl 1:S11-S66.

14. Sinclair AJ, Paolisso G, Castro M, et al. European Diabetes Working Party for Older People 2011 clinical guidelines for type 2 diabetes mellitus. Executive summary. Diabetes Metab. 2011;37 Suppl 3: S27-S38.

15. Nathan DM, Buse JB, Davidson MB, et al. Management of hyperglycemia in type 2 diabetes: A consensus algorithm for the initiation and adjustment of therapy: a consensus statement from the American Diabetes Association and the European Association for the Study of Diabetes. Diabetes Care. 2006;29(8):1963-1972.

16. American Diabetes Association, Bantle JP, Wylie-Rosett J, et al. Nutrition recommendations and interventions for diabetes: a position statement of the American Diabetes Association. Diabetes Care. 2008;31 Suppl 1:S61-S78.

17. Miller CK, Edwards L, Kissling G, Sanville L. Nutrition education improves metabolic outcomes among older adults with diabetes mellitus: results from a randomized controlled trial. Prev Med. 2002; 34(2):252-259.

18. Sigal RJ, Kenny GP, Wasserman DH, Castaneda-Sceppa C. Physical activity/exercise and type 2 diabetes. Diabetes Care. 2004;27(10): $2518-2539$

19. Lindeman RD, Tobin J, Shock NW. Longitudinal studies on the rate of decline in renal function with age. J Am Geriatr Soc. 1985;33(4):278-285.

20. O'Malley K, Crooks J, Duke E, Stevenson IH. Effect of age and sex on human drug metabolism. Br Med J. 1971;3(5775):607-609.

21. Turnheim K. Drug dosage in the elderly. Is it rational? Drugs Aging. 1998;13(5):357-379.

22. Fravel MA, McDanel DL, Ross MB, et al. Special considerations for treatment of type 2 diabetes mellitus in the elderly. Am J Health Sys Pharm. 2011;68(6):500-509.

23. Bailey CJ. Biguanides and NIDDM. Diabetes Care. 1992;15(6): 755-772.

24. Bailey CJ, Turner RC. Metformin. N Engl J Med. 1996;334(9): 574-579.

25. Stumvoll M, Nurjhan N, Perriello G, et al. Metabolic effects of metformin in non-insulin-dependent diabetes mellitus. $N$ Engl J Med. 1995;333(9):550-554.

26. No authors listed. United Kingdom Prospective Diabetes Study (UKPDS). 13: Relative efficacy of randomly allocated diet, sulphonylurea, insulin, or metformin in patients with newly diagnosed non-insulin dependent diabetes followed for three years. BMJ. 1995;310(6972):83-88.

27. DeFronzo RA, Goodman AM. Efficacy of metformin in patients with non-insulin-dependent diabetes mellitus. The Multicenter Metformin Study Group. N Engl J Med. 1995;333(9):541-549.

28. Saenz A, Fernandez-Esteban I, Mataix A, et al. Metformin monotherapy for type 2 diabetes mellitus. Cochrane Database Syst Rev. 2005;(3):CD002966.

29. Setter SM, Iltz JL, Thams J, Campbell RK. Metformin hydrochloride in the treatment of type 2 diabetes mellitus: A clinical review with a focus on dual therapy. Clin Ther. 2003;25(12):2991-3026.

30. de Jager J, Kooy A, Lehert P, et al. Long term treatment with metformin in patients with type 2 diabetes and risk of vitamin B-12 deficiency: randomised placebo controlled trial. BMJ. 2010;340:c2181.

31. Stang M, Wysowski DK, Butler-Jones D. Incidence of lactic acidosis in metformin users. Diabetes Care. 1999;22(6):925-927.

32. Salpeter SR, Greyber E, Pasternak GA, Salpeter EE. Risk of fatal and nonfatal lactic acidosis with metformin use in type 2 diabetes mellitus. Cochrane Database Syst Rev. 2010;(4):CD002967.

33. Sirtori CR, Pasik C. Re-evaluation of a biguanide, metformin: mechanism of action and tolerability. Pharmacol Res. 1994;30(3):187-228.

34. Shaw JS, Wilmot RL, Kilpatrick ES. Establishing pragmatic estimated GFR thresholds to guide metformin prescribing. Diabet Med. 2007;24(10):1160-1163.
35. Warren RE, Strachan MW, Wild S, McKnight JA. Introducing estimated glomerular filtration rate (eGFR) into clinical practice in the UK: implications for the use of metformin. Diabet Med. 2007;24(5): 494-497.

36. Hermann LS, Scherstén B, Bitzén PO, et al. Therapeutic comparison of metformin and sulfonylurea, alone and in various combinations. A doubleblind controlled study. Diabetes Care. 1994;17(10):1100-1109.

37. Bressler R, Johnson DG. Pharmacological regulation of blood glucose levels in non-insulin-dependent diabetes mellitus. Arch Intern Med. 1997;157(8):836-848.

38. Neumiller JJ, Setter SM. Pharmacologic management of the older patient with type 2 diabetes mellitus. Am J Geriatr Pharmacother. 2009;7(6):324-342.

39. Shorr RI, Ray WA, Daugherty JR, Griffin MR. Individual sulfonylureas and serious hypoglycemia in older people. J Am Geriatr Soc. 1996;44(7):751-755.

40. Shorr RI, Ray WA, Daugherty JR, Griffin MR. Incidence and risk factors for serious hypoglycemia in older persons using insulin or sulfonylureas. Arch Intern Med. 1997;157(15):1681-1686.

41. No authors listed. A study of the effects of hypoglycemia agents on vascular complications in patients with adult-onset diabetes. VI. Supplementary report on nonfatal events in patients treated with tolbutamide. Diabetes. 1976;25(12):1129-1153.

42. Garratt KN, Brady PA, Hassinger NL, et al. Sulfonylurea drugs increase early mortality in patients with diabetes mellitus after direct angioplasty for acute myocardial infarction. J Am Coll Cardiol. 1999;33(1):119-124.

43. Malmberg K. Prospective randomised study of intensive insulin treatment on long term survival after acute myocardial infarction in patients with diabetes mellitus. DIGAMI (Diabetes Mellitus, Insulin Glucose Infusion in Acute Myocardial Infarction) Study Group. BMJ. 1997;314(7093):1512-1515.

44. Simpson SH, Majumdar SR, Tsuyuki RT, et al. Dose-response relation between sulfonylurea drugs and mortality in type 2 diabetes mellitus: a population-based cohort study. CMAJ. 2006;174(2):169-174.

45. Roumie CL, Hung AM, Greevy RA, et al. Comparative effectiveness of sulfonylurea and metformin monotherapy on cardiovascular events in type 2 diabetes mellitus: a cohort study. Ann Intern Med. 2012;157(6): 601-610.

46. Stevens RJ, Coleman RL, Adler AI, et al. Risk factors for myocardial infarction case fatality and stroke case fatality in type 2 diabetes: UKPDS 66. Diabetes Care. 2004;27(1):201-207.

47. Hemmingsen B, Schroll JB, Lund SS, et al. Sulphonylurea monotherapy for patients with type 2 diabetes mellitus. Cochrane Database Syst Rev. 2013;4:CD009008

48. Wolffenbuttel BH, Landgraf R. A 1-year multicenter randomized double-blind comparison of repaglinide and glyburide for the treatment of type 2 diabetes. Dutch and German Repaglinide Study Group. Diabetes Care. 1999;22(3):463-467.

49. Prandin (repaglinide) tablets $(0.5,1 \mathrm{and} 2 \mathrm{mg})$ [prescribing information]. Princeton, NJ: Novo Nordisk Inc.; 2010.

50. Yki-Järvinen H. Thiazolidinediones. $N$ Engl J Med. 2004;351(11): 1106-1118.

51. Grey A. Skeletal consequences of thiazolidinedione therapy. Osteoporos Int. 2008;19(2):129-137.

52. Colmers IN, Bowker SL, Majumdar SR, Johnson JA. Use of thiazolidinediones and the risk of bladder cancer among people with type 2 diabetes: a meta-analysis. CMAJ. 2012;184(12):E675-E683.

53. Lipscombe LL, Gomes T, Lévesque LE, et al. Thiazolidinediones and cardiovascular outcomes in older patients with diabetes. JAMA. 2007;298(22):2634-2643.

54. Winkelmayer WC, Setoguchi S, Levin R, Solomon DH. Comparison of cardiovascular outcomes in elderly patients with diabetes who initiated rosiglitazone vs pioglitazone therapy. Arch Intern Med. 2008;168(21): 2368-2375.

55. Juurlink DN, Gomes T, Lipscombe LL, et al. Adverse cardiovascular events during treatment with pioglitazone and rosiglitazone: population based cohort study. BMJ. 2009;339:b2942. 
56. Graham DJ, Ouellet-Hellstrom R, MaCurdy TE, et al. Risk of acute myocardial infarction, stroke, heart failure, and death in elderly Medicare patients treated with rosiglitazone or pioglitazone. JAMA. 2010;304(4): 411-418.

57. Home PD, Pocock SJ, Beck-Nielsen H, et al. Rosiglitazone evaluated for cardiovascular outcomes in oral agent combination therapy for type 2 diabetes (RECORD): a multicentre, randomised, open-label trial. Lancet. 2009;373(9681):2125-2135.

58. US Food and Drug Administration [homepage on the Internet]. FDA Drug Safety Communication: FDA requires removal of some prescribing and dispensing restrictions for rosiglitazone-containing diabetes medicines. Available from: http://www.fda.gov/Drugs/DrugSafety/ ucm376389.htm. Assessed May 10, 2014.

59. Schwartz AV, Sellmeyer DE, Vittinghoff E, et al. Thiazolidinedione use and bone loss in older diabetic adults. J Clin Endocrinol Metab. 2006;91(9):3349-3354.

60. Habib ZA, Havstad SL, Wells K, et al. Thiazolidinedione use and the longitudinal risk of fractures in patients with type 2 diabetes mellitus. J Clin Endocrinol Metab. 2010;95(2):592-600.

61. van de Laar FA, Lucassen PL, Akkermans RP, et al. Alpha-glucosidase inhibitors for patients with type 2 diabetes: results from a Cochrane systematic review and meta-analysis. Diabetes Care. 2005;28(1): 154-163.

62. Holman RR, Cull CA, Turner RC. A randomized double-blind trial of acarbose in type 2 diabetes shows improved glycemic control over 3 years (UK Prospective Diabetes Study 44). Diabetes Care. 1999;22(6):960-964.

63. Campbell RK. Rationale for dipeptidyl peptidase 4 inhibitors: A new class of oral agents for the treatment of type 2 diabetes mellitus. Ann Pharmacother. 2007;41(1):51-60.

64. Amori RE, Lau J, Pittas AG. Efficacy and safety of incretin therapy in type 2 diabetes: systematic review and meta-analysis. JAMA. 2007;298(2):194-206

65. Scirica BM, Bhatt DL, Braunwald E, et al. Saxagliptin and cardiovascular outcomes in patients with type 2 diabetes mellitus. $N$ Engl J Med. 2013;369(14):1317-1326.

66. US Food and Drug Administration [homepage on the Internet]. Information for Healthcare Professionals - Acute pancreatitis and sitagliptin (marketed as Januvia and Janumet). Available from: http:// www.fda.gov/Drugs/DrugSafety/PostmarketDrugSafetyInformationfo rPatientsandProviders/DrugSafetyInformationforHeathcareProfession als/ucm 183764.htm. Accessed October 5, 2009.

67. Merck - Highlights of prescribing information: Januvia [homepage on the Internet]. Available from: http://www.merck.com/product/usa/ pi_circulars/j/januvia/januvia_pi.pdf. Accessed December 1, 2013.

68. Bergman AJ, Cote J, Yi B, et al. Effect of renal insufficiency on the pharmacokinetics of sitagliptin, a dipeptidyl peptidase-4 inhibitor. Diabetes Care. 2007;30(7):1862-1864.

69. Clar C, Gill JA, Court R, Waugh N. Systematic review of SGLT2 receptor inhibitors in dual or triple therapy in type 2 diabetes. $B M J$ Open. 2012;2(5):pii:e001007.

70. Vasilakou D, Karagiannis T, Athanasiadou E, et al. Sodium-glucose cotransporter 2 inhibitors for type 2 diabetes: a systematic review and meta-analysis. Ann Intern Med. 2013;159(4):262-274.

71. US Food and Drug Administration [homepage on the Internet]. FDA News Release: FDA approves Invokana to treat type 2 diabetes, Mar 2013. Available from: http://www.fda.gov/NewsEvents/Newsroom/ PressAnnouncements/ucm345848.htm. Accessed May 22, 2014.

72. US Food and Drug Administration [homepage on the Internet]. FDA News Release: FDA approves Farxiga to treat type 2 diabetes, Jan 2014. Available from: http://www.fda.gov/NewsEvents/ Newsroom/PressAnnouncements/ucm380829.htm. Accessed May 22, 2014.

73. Rosenstock J, Aggarwal N, Polidori D, et al. Dose-ranging effects of canagliflozin, a sodium-glucose cotransporter 2 inhibitor, as add-on to metformin in subjects with type 2 diabetes. Diabetes Care. 2012;35(6): $1232-1238$.
74. Schernthaner G, Gross JL, Rosenstock J, et al. Canagliflozin compared with sitagliptin for patients with type 2 diabetes who do not have adequate glycemic control with metformin plus sulfonylurea: a 52-week randomized trial. Diabetes Care. 2013;36(9):2508-2515.

75. Cefalu WT, Leiter LA, Yoon KH, et al. Efficacy and safety of canagliflozin versus glimepiride in patients with type 2 diabetes inadequately controlled with metformin (CANTATA-SU): 52 week results from a randomised, double-blind, phase 3 non-inferiority trial. Lancet. 2013;382(9896):941-950.

76. Nyirjesy P, Zhao Y, Ways K, Usiskin K. Evaluation of vulvovaginal symptoms and Candida colonization in women with type 2 diabetes mellitus treated with canagliflozin, a sodium glucose co-transporter 2 inhibitor. Curr Med Res Opin. 2012;28(7):1173-1178.

77. Musso G, Gambino R, Cassader M, Pagano G. A novel approach to control hyperglycemia in type 2 diabetes: sodium glucose co-transport (SGLT) inhibitors: systematic review and meta-analysis of randomized trials. Ann Med. 2012;44(4):375-393.

78. Nauck MA, Niedereichholz U, Ettler R, et al. Glucagon-like peptide 1 inhibition of gastric emptying outweighs its insulinotropic effects in healthy humans. Am J Physiol. 1997;273(5 Pt1):E981-E988.

79. Koliaki C, Doupis J. Incretin-based therapy: a powerful and promising weapon in the treatment of type 2 diabetes mellitus. Diabetes Ther. 2011;2(2):101-121.

80. DeFronzo RA, Ratner RE, Han J, et al. Effects of exenatide (exendin-4) on glycemic control and weight over 30 weeks in metformin-treated patients with type 2 diabetes. Diabetes Care. 2005;28(5):1092-1100.

81. Buse JB, Henry RR, Han J, et al. Effects of exenatide (exendin-4) on glycemic control over 30 weeks in sulfonylurea-treated patients with type 2 diabetes. Diabetes Care. 2004;27(11):2628-2635.

82. Moretto TJ, Milton DR, Ridge TD, et al. Efficacy and tolerability of exenatide monotherapy over 24 weeks in antidiabetic drug-naive patients with type 2 diabetes: a randomized, double-blind, placebo-controlled, parallel-group study. Clin Ther. 2008;30(8):1448-1460.

83. Buse JB, Nauck M, Forst T, et al. Exenatide once weekly versus liraglutide once daily in patients with type 2 diabetes (DURATION-6): a randomised, open-label study. Lancet. 2013;381(9861):117-124.

84. Fineman MS, Shen LZ, Taylor K, et al. Effectiveness of progressive dose-escalation of exenatide (exendin-4) in reducing dose-limiting side effects in subjects with type 2 diabetes. Diabetes Metab Res Rev. 2004;20(5):411-417.

85. US Food and Drug Administration [homepage on the Internet]. Postmarket drug safety information for patients and providers. Information for healthcare professionals: Exenatide (marketed as Byetta) 8/2008 update. Available from: http://www.fda.gov/Drugs/DrugSafety/P ostmarketDrugSafetyInformationforPatientsandProviders/ucm124713. htm. Accessed December 4, 2013.

86. US Food and Drug Administration [homepage on the Internet]. MedWatch. The FDA Safety Information and Adverse Event Reporting Program: Safety Information - Byetta (exenatide) - Renal Failure. Available from: http://www.fda.gov/Safety/MedWatch/SafetyInformation/SafetyAlertsforHumanMedicalProducts/ucm188703.htm. Accessed December 04, 2013.

87. Kong MF, Stubbs TA, King P, et al. The effect of single doses of pramlintide on gastric emptying of two meals in men with IDDM. Diabetologia. 1998;41(5):577-583.

88. Fineman MS, Koda JE, Shen LZ, et al. The human amylin analog, pramlintide, corrects postprandial hyperglucagonemia in patients with type 1 diabetes. Metabolism. 2002;51(5):636-641.

89. Hollander PA, Levy P, Fineman MS, et al. Pramlintide as an adjunct to insulin therapy improves long-term glycemic and weight control in patients with type 2 diabetes: a 1-year randomized controlled trial. Diabetes Care. 2003;26(3):784-790.

90. Palumbo PJ. The case for insulin treatment early in type 2 diabetes. Cleve Clin J Med. 2004;71(5):385-394.

91. Reza M, Taylor CD, Towse K, et al. Insulin improves well-being for selected elderly type 2 diabetic subjects. Diabetes Res Clin Pract. 2002;55(3):201-207. 
92. Inzucchi SE, Bergenstal RM, Buse JB, et al. (2012) Management of hyperglycemia in type 2 diabetes: a patient-centered approach. Position statement of the American Diabetes Association (ADA) and the European Association for the Study of Diabetes (EASD). Diabetes Care. 2012;35(6):1364-1379.

93. Rodbard HW, Jellinger PS, Davidson JA, et al. Statement by an American Association of Clinical Endocrinologists/American College of Endocrinology consensus panel on type 2 diabetes mellitus: An algorithm for glycemic control. Endocr Pract. 2009;15(6): 540-559.

94. Horvath K, Jeitler K, Berghold A, et al. Long-acting insulin analogues versus NPH insulin (human isophane insulin) for type 2 diabetes mellitus. Cochrane Database Syst Rev. 2007;(2):CD005613.

95. Garber AJ, Clauson P, Pedersen CB, Kolendorf K. Lower risk of hypoglycemia with insulin detemir than with neutral protamine Hagedorn insulin in older persons with type 2 diabetes: A pooled analysis of phase III trials. J Am Geriatr Soc. 2007;55(11):1735-1740.

96. Hermansen K, Davies M, Derezinski T, et al. A 26-week, randomized, parallel, treat-to-target trial comparing insulin detemir with NPH insulin as add-on therapy to oral glucose-lowering drugs in insulinnaive people with type 2 diabetes. Diabetes Care. 2006;29(6): 1269-1274.

97. Nathan DM, Buse JB, Davidson MB, et al. Medical Management of Hyperglycemia in Type 2 Diabetes: A Consensus Algorithm for the Initiation and Adjustment of Therapy: A consensus statement of the American Diabetes Association and the European Association for the Study of Diabetes. Diabetes Care. 2009;32(1):193-203.

98. $\mathrm{Ng} \mathrm{JM}$, Cooke M, Bhandari S, et al. The effect of iron and erythropoietin treatment on the A1C of patients with diabetes and chronic kidney disease. Diabetes Care. 2010;33(11):2310-2313.
99. Young MJ, Boulton AJ, MacLeod AF, et al. A multicentre study of the prevalence of diabetic peripheral neuropathy in the United Kingdom hospital clinic population. Diabetologia. 1993;36(2):150-154.

100. Aronow WS, Fleg JL, Pepine CJ, et al. ACCF/AHA 2011 expert consensus document on hypertension in the elderly: a report of the American College of Cardiology Foundation Task Force on Clinical Expert Consensus Documents. Circulation. 2011;123(21):2434-2506.

101. Heart Protection Study Collaborative Group. MRC/BHF Heart Protection Study of cholesterol lowering with simvastatin in 20,536 high-risk individuals: a randomised placebo-controlled trial. Lancet. 2002;360(9356):7-22.

102. Howard BV, Howard WJ. The compelling case for smoking cessation in diabetics. Circulation. 1990;82(1):299-301.

103. No authors listed. Collaborative overview of randomised trials of antiplatelet therapy - I: Prevention of death, myocardial infarction, and stroke by prolonged antiplatelet therapy in various categories of patients. Antiplatelet Trialists' Collaboration. BMJ. 1994;308(6921): 81-106.

104. Hebert LE, Scherr PA, Bienias JL, et al. Alzheimer disease in the US population: prevalence estimates using the 2000 census. Arch Neurol. 2003;60(8):1119-1122.

105. Lustman PJ, Clouse RE. Treatment of depression in diabetes: impact on mood and medical outcome. J Psychosom Res. 2002;53(4): 917-924.

106. Lustman PJ, Freedland KE, Griffith LS, et al. Predicting response to cognitive behavior therapy of depression in type 2 diabetes. Gen Hosp Psychiatry. 1998;20(5):302-306.

\section{Publish your work in this journal}

Diabetes, Metabolic Syndrome and Obesity: Targets and Therapy is an international, peer-reviewed open-access journal committed to the rapid publication of the latest laboratory and clinical findings in the fields of diabetes, metabolic syndrome and obesity research. Original research, review, case reports, hypothesis formation, expert opinion and commentaries are all considered for publication. The manuscript management system is completely online and includes a very quick and fair peer-review system, which is all easy to use. Visit http://www.dovepress.com/testimonials.php to read real quotes from published authors. 